\title{
Estimation of Serum Levels of VEGF \& SVEGFR-1 (sFLT-1) in Preeclampsia
}

\author{
Khrieketouzo Atou Chielie ${ }^{1}$, Renu Dhingra ${ }^{2}$, Neerja Bhatla ${ }^{3}$ \\ ${ }^{1}$ Department of Anatomy, Sikkim Manipal Instiute of Medical Sciences, Tadong \\ Gangtok, East Sikkim, India. ${ }^{2}$ Department of Anatomy, AIIMS, Delhi, India. \\ ${ }^{3}$ Department of Anatomy, AIIMS, Delhi, India.
}

\section{ABSTRACT}

\section{BACKGROUND}

Previously in normotensive non-proteinuric pregnant women, preeclampsia which is characterized by hypertension and proteinuria has been the main reason for foetal and maternal mortality and morbidity. Previous studies have shown that preeclampsia occurs mostly when the placenta is present and remits after its delivery and since angiogenic factors are involved in placentation, it is of immense importance to study the levels of circulating angiogenic factors during preeclampsia.

\section{METHODS}

Blood samples of 20 preeclamptic and 20 normotensive, non-proteinuric pregnant women were collected and stored at $-20 \stackrel{\circ}{\circ}$. Enzyme linked immunosorbent assay was used to measure the serum level of VEGF. Various concentrations of the standard VEGF (15.6 - $1000 \mathrm{pg} / \mathrm{ml})$ and sFlt-1 (31.2 - $20000 \mathrm{pg} / \mathrm{ml})$ were used.

\section{RESULTS}

In the preeclamptic pregnant women the levels of free VEGF were found to be significantly lower than the VEGF level of control women. The levels of VEGF in the maternal serum of preeclamptic patients were $38.06 \pm 7.18 \mathrm{pg} / \mathrm{ml}$ (mean $\pm \mathrm{SD}$ ).

\section{CONCLUSIONS}

The present study concludes that in preeclamptic patients, low levels of VEGF shows a potential connection between the circulating angiogenic factors and development of the clinical manifestations of preeclampsia.

\section{KEY WORDS}

Preeclampsia, Placenta, Vascular Endothelial Growth Factor (VEGF)
Corresponding Author: Dr. Khrieketouzo Atou Chielie, Assistant Professor, Department of Anatomy, Sikkim Manipal Institute of Medical Sciences, $5^{\text {th }}$ Mile Tadong, Gangtok-737102, East Sikkim, India. E-mail: kcchielie@yahoo.co.in

DOI: $10.14260 / j e m d s / 2020 / 197$

Financial or Other Competing Interests: None.

How to Cite This Article:

Chielie KA, Dhingra R, Bhatla N. Estimation of serum levels of VEGF \& SVEGFR-1 (sFLT1) in preeclampsia. J. Evolution Med. Dent. Sci. 2020;9(12):913-918, DOI: $10.14260 /$ jemds/2020/197

Submission 30-11-2019, Peer Review 25-02-2020, Acceptance 04-03-2020, Published 23-03-2020.

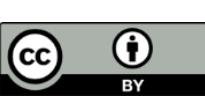




\section{BACKGROUND}

The leading cause of maternal \& foetal morbidity and mortality affecting approximately 2 - $8 \%$ of pregnancies on or after 20 weeks of gestation is preeclampsia.1,2 Primiparous women are affected more in the latter half of pregnancy with hypertension and proteinuria who were previously normotensive and non proteinuric. Without treatment, the condition of preeclampsia can lead to a state known as eclampsia. An incidence of 8.5 million cases every year worldwide has been estimated. In the past two decades, a lot of studies has been carried out on preeclampsia, but it continues to be a major health concern during pregnancy. Hypertension and proteinuria which defines preeclampsia seem to represent the late stage of a disease which happens very early in pregnancy. Many opinions have been put forward about the cause of preeclampsia and it is most probably many different initial insults converge on a common pathway which ultimately leads to preeclampsia. It has been observed that preeclampsia occurs only whenever the placenta is present and almost always remits after it's delivery. ${ }^{3}$ Because of this association of the placenta in preeclampsia, a lot of research in the past was focussed on placental vascular remodelling abnormalities that may play a role in the disease. One proposed explanation suggests that because of insufficient local concentrations of angiogenic factors, including VEGF (Vascular Endothelial Growth Factor) and PGIF (Placental Growth Factor), which are present in increased levels during placentation, there is impaired transformation and invasion of cytotrophoblasts. ${ }^{4}$ $\alpha v \beta 3$ integrin, a molecule expressed by endothelial cells and which is associated with invasion of the cytotrophoblasts and angiogenesis is also induced by VEGF 5 . Also, cytotrophoblasts possesses VEGF receptors, which includes Fms-like tyrosine kinase (Flt 1) receptor (also known as the VEGF receptor-1). ${ }^{6}$

During 6 weeks postfertilization it has been noticed, there are high levels of Flt 1 found in invasive cytotrophoblast. For invasion the interaction of Flt 1 receptor with VEGF and PIGF has been regarded crucial. Decreased expression of integrin $\alpha 1$ and fewer cell interactions supports the possibility. In the culture medium when an Flt $1-F c$ fusion protein which blocks binding of VEGF and PIGF to the Flt 1 receptor, the invasive capacity of these defective cells was observed in human cytotrophoblast in vitro ${ }^{6}$. Previous studies have shown that the levels of VEGF messenger RNA were decreased in preeclamptic placentas which supported the presumption that optimal levels of VEGF are required for favourable invasion and normal placentation. In the human placenta, the Flt 1 produced is in a soluble form (sFlt1), which is produced by alternative splicing in the latter half of gestation. The cytoplasmic domain and transmembrane of Flt 1 is absent in the soluble form sFlt and is dispersed in huge amounts in the blood 7, where the levels of free VEGF via soluble antagonism of both factors are reduced. It has been observed that more sFlt1 were released from cytotrophoblasts isolated from preeclamptic placentas compared to cytotrophoblasts from normal placentas, ${ }^{6}$ and there was also upregulation of sFlt1 messenger RNA in preeclamptic placentas. ${ }^{8}$ Since different angiogenic factors are involved during placentation, it will be very intriguing to study the levels of circulating angiogenic factors during preeclampsia and to relate whether it is the cause or effect of the disease. Also, it has been observed in previous studies that there was a great variation in the elevated levels of sFlt1,9,10,11,12 which may be due to racial difference, geographical and socioeconomic. ${ }^{13}$

Thus, it is important in a given population, to scrutinize the baseline value of circulating angiogenic factors, so that we can determine a threshold value for predicting the disease. And so a study was planned to estimate the level of VEGF (Angiogenic factor) in the sera of preeclamptic patients in the Indian population.

\section{METHODS}

A total number of 40 patients were enrolled, out of which 20 were preeclamptic patients and 20 were normotensive, nonproteinuric pregnant women who served as control. The blood samples were already collected before and stored at $-20 \mathrm{C}$. The cases and controls were selected from the antenatal clinic and the inpatient ward of the Department of Obstetrics and Gynaecology, All India Institute of Medical Sciences, New Delhi, India. The preeclamptic women after the clinical diagnosis were immediately enrolled as cases and the normotensive, non-proteinuric pregnant women without any other medical complications were enrolled as control group. For the present study the samples were anonymised at the time of selection. The ethical clearance for the use of such samples has been obtained by Institutes Ethical Committee (IEC), All India Institute of Medical Sciences. Pre-eclampsia was defined according to the research definition criteria of the International Society for the Study of Hypertension in pregnancy (NHBPEP/ ISSHP), ${ }^{14}$ systolic and diastolic blood pressure of 140 and $90 \mathrm{~mm} \mathrm{Hg}$ and above respectively, in at least two consecutive measurements and at least 4 hours apart occurring after twentieth week of gestation and accompanied by proteinuria $(\geq 300 \mathrm{mg}$ per litre in a 24 hour urine collection $/ \geq 1+$ on a urine dipstick)

\section{Inclusion Criteria}

Females with pregnancy induced hypertension (PIH) after 20 weeks of gestation who were considered as preeclamptic as per ISSHP guidelines were included as normotensive and patient group, for control group non-proteinuric pregnant women without any complication in pregnancy were taken.

\section{Exclusion Criteria}

Patients with the following abnormalities were excluded from the study: Chronic hypertension, Chorioamnionitis Renal disease, Pre-gestational diabetes, Thyroid disease, Cardiac disease, Active asthma, Pre-existing seizure disorder 2 . Patients who refused to give consent.

\section{Sample Collection}

$10 \mathrm{ml}$ of venous blood was collected and centrifuged at 3000 rpm for 20 minutes and the serum was then separated and stored in aliquots at $-20^{\circ} \mathrm{C}$. For immunological techniques the serum samples were stored-

1. Estimation of serum levels of pro- angiogenic factor by sandwich ELISA.

2. Estimation of serum levels of VEGF in pre-eclamptic patients and control group. The serum level of VEGF was measured by a sandwich type enzyme linked immunosorbent assay (ELISA; Quantitative ${ }^{\circledR}$ human 
VEGF and Quantikine ${ }^{\circledR}$ human sVEGFR1/sFlt-1, R\&D Systems Inc., Minneapolis, MN, USA).

3. Various concentrations of the standard VEGF (15.6-1000 $\mathrm{pg} / \mathrm{ml}$ ) was used. The readings of absorbance were plotted against the various concentration of VEGF to produce standard curve. The concentration of VEGF in each sample was determined by extending a horizontal line from the absorbance value on the $y$-axis to the standard curve and from the point of intersection to the $\mathrm{x}$-axis (vertical line). The corresponding concentration was read from the $\mathrm{x}$ - axis. The minimum detectable level for VEGF was $7 \mathrm{pg} / \mathrm{ml}$ according to the kit. The intra assay variation and inter assay variation were $4.5 \%$ and $7.0 \%$ for VEGF.

\section{Statistical Analysis}

Difference in the variables among two groups will be analysed by one-way analysis of variance (ANOVA). SPSS 20 will be used for data analysis. $\mathrm{p} \leq 0.005$ will be considered significant.

\section{RESULTS}

Estimation of serum VEGF in pre-eclamptic and control group. In this study maternal serum of 40 pregnant women were analysed. Of these, 20 were pre-eclamptic patients as per ISSHP guidelines and 20 were normotensive, non-proteinuric pregnant women, who served as control. Maternal serum levels of VEGF in pre-eclamptic patients and control women [Table. 1]. In the maternal serum of preeclamptic patients the levels of VEGF were $38.06 \pm 7.18 \mathrm{pg} / \mathrm{ml}$ (mean $\pm \mathrm{SD}$ ). In the maternal serum of control group, the levels of VEGF were $134.04 \pm 22.70 \mathrm{pg} / \mathrm{ml}$ (mean \pm SD). Serum levels of VEGF with patients with preeclampsia was much lower than control group ( $\mathrm{p}<0.001)$.

\begin{tabular}{|c|c|c|c|}
\hline $\begin{array}{c}\text { Study Groups } \\
\text { Serum Levels of } \\
\text { VGEF }\end{array}$ & $\begin{array}{c}\text { Preeclamptic Sera } \\
\text { Mean } \pm \text { SD }(\mathbf{n = 2 0 )}\end{array}$ & $\begin{array}{c}\text { Control Sera } \\
\text { Mean } \pm \text { SD (n=20) }\end{array}$ & $\begin{array}{c}\text { Statistical } \\
\text { Significance } \\
\text { (p Value) }\end{array}$ \\
\hline VEGF ( pg/ml) & $38.06 \pm 7.18$ & $134.04 \pm 22.70$ & $<0.001^{*}$ \\
\hline \multicolumn{3}{|c|}{$\begin{array}{c}\text { Table 1. Maternal Serum Levels of VEGF in } \\
\text { Preeclamptic and Control Women }\end{array}$} \\
\hline $\begin{array}{l}\text { n = number of subjects, Data presented as Mean (SD), Student's t-test. * Statistical } \\
\text { significance, p<0.05. }\end{array}$ \\
\hline
\end{tabular}

\begin{tabular}{|c|c|c|c|}
\hline Study Gri & \multirow{2}{*}{$\begin{array}{c}\text { Preeclamptic Sera } \\
\text { Mean } \pm \text { SD } \\
(n=20)\end{array}$} & \multirow{2}{*}{$\begin{array}{c}\text { Control Sera } \\
\text { Mean } \pm \text { SD } \\
(n=20)\end{array}$} & \multirow{2}{*}{$\begin{array}{c}\text { Statistical } \\
\text { Significance } \\
\text { (p Value) }\end{array}$} \\
\hline Serum Levels of sFlt- 1 & & & \\
\hline (III) & .01 & 3030 & \\
\hline \multicolumn{4}{|c|}{$\begin{array}{l}\text { Table 2. Maternal Serum Levels of sFlt-1 in } \\
\text { Preeclamptic and Control Women }\end{array}$} \\
\hline \multicolumn{4}{|c|}{$\begin{array}{l}=\text { number of subjects, Data presented as } \\
\text { gnificance, } p<0.05 \text {. }\end{array}$} \\
\hline
\end{tabular}

The levels of sFlt- 1 in the maternal serum of preeclamptic patients were $6785.25 \pm 1677.01 \mathrm{pg} / \mathrm{ml}$ (mean $\pm \mathrm{SD}$ ). The levels of sFlt-1 in the maternal serum of control group were $3030.29 \pm 956.35 \mathrm{pg} / \mathrm{ml}($ mean $\pm \mathrm{SD})$. The serum levels of sFlt1 were significantly higher in women with preeclampsia that in control $(\mathrm{p}<0.001)$.

\section{DISCUSSION}

In women with preeclampsia increased levels of VEGF were reported by several authors, $15,16,17$ whereas other authors have reported decreased levels, ${ }^{18,8}$ a discrepancy which probably has to do with the methodology. ${ }^{8}$ Studies conducted by various authors in women with PE have shown increased systemic VEGF levels $15,16,17$ and reports of decreased levels by other authors, ${ }^{18,8}$ often leading to discrepancy which might be due to procedures followed. ${ }^{8}$ Evidences shows that antagonism in VEGF may have a role in hypertension and proteinuria. ${ }^{19,8}$ The effectively circulating VEGF which is reflected accurately by the Free VEGF levels, are substantially lower than total VEGF levels. Therefore, normal to high total VEGF levels perhaps induced by placental hypoxia characterises preeclampsia and excess of SFlt1 which antagonizes the VEGF effects in the maternal endothelial cell function, formation of placental vasculature and health of trophoblast cells. ${ }^{8}$ Evidences of different levels of VEGF have its role in proteinuria and hypertension.

\section{Maternal Serum Levels of VEGF in Pre-Eclamptic Patients and Control Women}

In the sera of pre-eclamptic pregnant women when compared to that of control women the levels of free VEGF were significantly decreased in this present study [mean \pm SD; 38.06 \pm 7.18 Vs $134.04 \pm 22.70, p<0.05$ ]. (Table. 1 ). In the endothelial cell proliferation, an important angiogenic factor is (VEGF) vascular endothelial growth factor. It plays an essential role in physiological vasculogenesis and vascular permeability 20 . VEGF has a molecular weight of $34-42 \mathrm{kDa}$, and is a disulphidelinked homodimeric, heparin binding glycoprotein ${ }^{21}$. It binds to tyrosine kinase receptors, namely Flt-1 (Also named VEGFR1) and to flk1 (also named KDR VEGFR2), present on endothelial cells and trophoblast cell membranes. ${ }^{22,23}$ The role of VEGF in preeclampsia has received considerable importance. Studies conducted by various authors in women with PE have shown increased systemic VEGF levels, 15,16,17 and reports of decreased levels by other authors, ${ }^{18,8}$ often leading to discrepancy which might be due to procedures followed. During pregnancy, unlike in the non-pregnant state, most VEGF is bound to circulating sFlt1 due to very high levels of the latter. It should also be mentioned that sFlt1 acts through its antagonism of both VEGF and placental growth factor (PIGF), since the VEGF antagonist sFlk1 does not produce the preeclampsia phenotype in pregnant rats ${ }^{8}$. The origin of the elevated VEGF levels has not been confirmed conclusively. Conflicting results have been reported regarding the regulation of the VEGF system in PE at the transcriptional and translational level in the placenta. 24,25,26,27 Most candidate genes and all genome-wide scans so far have focused mainly on maternal genetic factors, but evidence is growing that the foetal gene load influences mother's susceptibility to preeclampsia ${ }^{28}$. Seen in this light, measuring VEGF levels in the umbilical vein and artery and investigating maternal and foetal VEGF polymorphisms would be more informative about possible associations between VEGF and PE. It has also been demonstrated that second trimester analysis of circulating VEGF appears to be a useful tool for the early identification of pregnant women at increased risk for developing severe, early onset P. ${ }^{29}$ 


\section{Maternal Serum Levels of sFlt-1 in Preeclamptic Patients and Control Women}

In the sera of preeclamptic women a significant increase in concentration of sFlt-1 was observed as compared to control in the present study [mean \pm SD; $6785 \pm 1677.01$ Vs $3030.29 \pm 956.35, \mathrm{p}<0.05]$. (Table. 2). The increased values of the sFlt-1 in this study are at par with previous studies which also showed high levels of sFlt- 1 in the serum of preeclamptic women though the increase is not same which may be attributed to ethnic and geographical variation.7,30,31 One possible explanation may be the inadequate perfusion of the foetoplacental unit causing hypoxia, which may lead to increased production of sFlt- 1 by placental trophoblast and later reflecting as raised sFlt-1 levels in maternal circulation. ${ }^{32,33}$ Angiogenic factors both stimulate angiogenesis and appear necessary for maintenance of endothelial health and integrity. ${ }^{34}$ Over expression of a soluble receptor for the angiogenic factors, placental growth factors and vascular endothelial growth factors has been reported in the placenta of women with preeclampsia. ${ }^{8}$ The soluble receptor, soluble fms-like tyrosine kinase (sFlt1) acts as an antagonist of VEGF and placental growth factor by binding and sequestering these growth factors from interaction with their receptors Flt1 and Flk1. In pregnancy the circulating concentration of SFlt1 was elevated and more so in preeclampsia. Furthermore, in rats, overexpression of this receptor resulted in preeclampsia -like syndrome 8 . Subsequently, it was found that even before preeclampsia become evident the sFlt1 was increased supporting a role in pathogenesis and raising the hope for a predictor of preeclampsia. ${ }^{7}$ SFlt 1 is a glycosylated protein, 90-100 kDa and a product of a Flt 1 gene. ${ }^{35}$ About 40 million years ago, origin of the molecule was suggested after detailed examination of the molecule revealed it was present only in primates including orangutan, rhesus, marmosets and chimpanzee but not prosimian tarsier or mouse lemur. In the fenestrated endothelium, the endothelium integrity and angiogenesis stimulation is done by the growth factor VEGF, present in the glomerular capillaries. ${ }^{34}$ In cancer treatment administration of VEGF antagonist which is associated with hypertension and proteinuria. ${ }^{36}$ Pathological changes were observed in rats with excess of sFlt1 manifested glomerular capillary injury which was very similar that was observed in the kidneys of women with preeclampsia. ${ }^{8}$ To the sites of endothelial injury VEGF recruits endothelial progenitor cells. ${ }^{37}$ Interestingly, in preeclampsia the circulating concentration of these cells is reduced. ${ }^{38}$

VEGF also plays an additional role in embryonic development as well as vasodilation, neurogenic and neurotropic activities. ${ }^{39,40}$ Appropriate concentration of such a potent agent must be maintained to avoid adverse effects ${ }^{41}$. Investigation of sFlt-e 15a by Sela and co-workers raised another possibility. ${ }^{42}$ In their studies, the sFlt1-e15a variant is termed sFlt. The major isoform of sFlt-e15a which is sFlt-13 was found to be predominant in the vascular smooth muscle. They proposed that the vascular smooth muscles and other organ were protected from the undesirable effects of VEGF, due to the excess production of the transcripts. In recent study of cancer metastasis which demonstrated that a subsequent reduction in free VEGF with increased sFlt1 normalized endothelial structure and function. ${ }^{43}$
Inappropriate or excessively located VEGF is checked by the production of sFlt- 1 which also had protective function and it is done by shifting the balance of production of sFlt-1 transcripts to the soluble form. Therefore, it can be concluded from the present study that a carefully regulated balance of VEGF, sFlt-1 and PIGF, which is important to maintain optimum level of angiogenesis which is important for proper placental vasculature and therefore successful placental circulation for maintaining normal pregnancy. As observed in the present study, any deviation of these angiogenic factors from the normal values will lead to disturbance in the blood flow in the placenta leading to conditions like preeclampsia.

\section{CONCLUSIONS}

In preeclamptic women the levels of sFlt-1 are increased and the levels of VEGF are decreased. In the maternal circulation the binding of VEGF to its normal receptors (VEGFR 1 and 2) is blocked by antiangiogenic factor sflt- 1 , thereby activating the apoptotic genes and promoting cell death by blocking the VEGF mediated cell signalling. In preeclamptic patients during the first trimester, the placenta secreted the sFlt-1 and it was elevated. For preeclampsia there is no screening marker currently. In the future, detection and treatment of preeclampsia are likely to evolve, due to in depth research of circulating anti angiogenic factors and their regulation can have potential clinical implication. As therapeutic options for preeclampsia, researchers are analysing various pharmacologic agent to counteract the effects of sFlt-1. Deliveries could be safely postponed for few weeks, if agents are effective in alleviating the manifestation, which would have a significant impact on neonatal morbidity and mortality.

\section{REFERENCES}

[1] Ghulmiyyah L, Sibai B. Maternal mortality from preeclampsia/eclampsia. Semin Perinatol 2012;36(1):56-9.

[2] Moodley J. Maternal deaths associated with hypertensive disorders of pregnancy: a population-based study. Hypertens Pregnancy 2004;23(3):247-56.

[3] Karumanchi SA, Bdolah Y. Hypoxia and sFlt-1 in preeclampsia: the "Chicken and Egg" question. Endocrinology 2004;145(11):4835-7.

[4] Sharkey AM, Charnock-Jones DS, Boocock CA, et al. Expression of mRNA for vascular endothelial growth factor in human placenta. J Reprod Fertil 1993;99(2):60915.

[5] Zhou Y, Damsky CH, Fisher SJ, et al. Preeclampsia is associated with failure of human cytotrophoblasts to mimic a vascular adhesion phenotype. One cause of defective endovascular invasion in this syndrome? J Clin Invest 1997;99(9):2152-64.

[6] Zhou Y, McMaster M, Woo K, et al. Vascular endothelial growth factor ligands and receptors that regulate human cytotrophoblast survival are dysregulated in severe preeclampsia and hemolysis, elevated liver enzymes and low platelets syndrome. Am J Pathol 2002;160(4):140523. 
[7] Levine RJ, Maynard SE, Qian C, et al. Circulating angiogenic factors and the risk of preeclampsia. $\mathrm{N}$ Engl J Med 2004;350:672-83.

[8] Maynard SE, Min JY, Merchan J, et al. Excess placental soluble fms-like tyrosine kinase 1 (sFlt1) may contribute to endothelial dysfunction, hypertension, and proteinuria in preeclampsia. J Clin Invest 2003;111:649-58.

[9] El-Salahy EM, Ahmed MI, El-Gharieb A, et al. New scope in angiogenesis: role of vascular endothelial growth factor (VEGF), NO, lipid peroxidation and vitamin $E$ in the pathophysiology of pre-eclampsia among Egyptian females. Clin Biochem 2001;34:323-9.

[10] Madazli R, Aydin S, Uludag S, et al. Maternal plasma levels of cytokines in normal and preeclampti pregnancies and their relationship with diastolic blood. 2003.

[11] Bussen S, Rieger L, Sutterlin M, et al. Plasma VEGF levels are increased in women with sever preeclampsi. Am J Obstet Gynecol 2003;192:734-41.

[12] Muy-Rivera M, Vadachkoria S, Woelk GB, et al. Maternal plasma VEGF, sVEGF-R1 and PlGF concentrations in preeclamptic and normotensive pregnant Zimbabwean women. Physiol Res 2005;54:611-22.

[13] López-Jaramillo P, Casas JP, Serrano N. Preeclampsia: from epidemiological observations to molecular mechanisms. Braz J Med Biol Res 2001;34:1227-35.

[14] Mark A. Zamorski, Lee a. Green,. University of Michigan Medical School, Ann Arbor, Michigan. Am Fam Physician. 2001 Jul 15;64(2):263-271.

[15] Baker PN, Davidge ST, Roberts JM, et al. Plasma from women with preeclampsia increases endothelial cell nitric oxide production. Hypertension 1995;26:244-8.

[16] Kupferminc MJ, Daniel Y, Englender T, et al. Vascular endothelial growth factor is increased in patients with preeclampsia. Am J Reprod Immunol 1997;38:302-6.

[17] Hunter A, Aitkenhead M, Caldwell C, et al. Serum levels of vascular endothelial growth factor in preeclamptic and normotensive pregnancy. Hypertension 2000;36:965-9.

[18] Lyall F, Greer I.A, Boswell F, et al. Suppression of serum vascular endothelial growth factor immunoreactivity in normal pregnancy and in pre-eclampsia. $\mathrm{Br} \mathrm{J}$ Obstet Gynaecol 1997;104:223-8.

[19] Koga K, Osuga Y, Yoshino O, et al. Elevated serum soluble vascular endothelial growth factor receptor 1 (sVEGFR-1) levels in women with preeclampsia. J Clin Endocrinol Metab 2003;88:2348-51.

[20] Ferrara N, Gerber HP. The role of vascular endothelial growth factor in angiogenesis. Acta Haematol 2001;106:148-56.

[21] Senger DR, Van de Water L, Brown LF, et al. Vascular permeability factor (VPF, VEGF) in tumor biology. Cancer Metastasis Rev 1993;12:303-24.

[22] De Vries C, Escobedo JA, Ueno H, et al. The fms-like tyrosine kinase, a receptor for vascular endothelial growth factor. Science 1992;255:989-91.

[23] Terman BI, Dougher-Vermazen M, Carrion ME, et al. Identification of the KDR tyrosine kinase as a receptor for vascular endothelial cell growth factor. Biochem Biophys Res Commun 1992;187(3):1579-86.

[24] Cooper JC, Sharkey AM, McLaren J, et al. Localization of vascular endothelial growth factor and its receptor, flt, in human placenta and decidua by immunohistochemistry. J Reprod Fertil 1995;105(2):205-13.
[25] Ranheim T, Staff AC, Henriksen T. VEGF mRNA is unaltered in decidual and placental tissues in preeclampsia at delivery. Acta Obstet Gynecol Scand 2001;80(2):93-8.

[26] Geva E, Ginzinger DG, Zaloudek CJ, et al. Human placental vascular development: vasculogenic and angiogenic (branching and nonbranching) transformation is regulated by vascular endothelial growth factor-A, angiopoietin-1, and angiopoietin-2. J Clin Endocrinol Metab 2002;87(9):4213-24.

[27] Trollmann R, Amann K, Schoof E, et al. Hypoxia activates the human placental vascular endothelial growth factor system in vitro and in vivo: up-regulation of vascular endothelial growth factor in clinically relevant hypoxic ischemia in birth asphyxia. Am J Obstet Gynecol 2003;188(2):517-23.

[28] Lachmeijer AMA, Dekker GA, Pals G, et al. Searching for preeclampsia genes: the current position. Eur J Obstet Gynecol Reprod Biol 2002;105(2):94-113.

[29] Polliotti BM, Fry AG, Saller DN, et al. Second-trimester maternal serum placental growth factor and vascular endothelial growth factor for predicting severe, earlyonset preeclampsia. Obstet Gynecol 2003;101(6):126674.

[30] Simas TAM, Crawford SL, Solitro MJ, et al. Angiogenic factors for the prediction of preeclampsia in high-risk women. Am J Obstet Gynecol 2007;197(3):244.e1-8.

[31] Woolcock J, Hennessy A, Xu B, et al. Soluble Flt-1 as a diagnostic marker of pre-eclampsia. Aust N Z J Obstet Gynaecol 2008;48(1):64-70.

[32] Noris M, Perico N, Remuzzi G. Mechanisms of disease: preeclampsia. Nat Clin Pract Nephrol 2005;1(2):98-114, quiz 120.

[33] Heydarian M, McCaffrey T, Florea L, et al. Novel splice variants of sFlt1 are upregulated in preeclampsia. Placenta 2009;30(3):250-5.

[34] Olsson AK, Dimberg A, Kreuger J, et al. VEGF receptor signalling - in control of vascular function. Nat Rev Mol Cell Biol 2006;7(5):359-71.

[35] Huckle WR, Roche RI. Post-transcriptional control of expression of sFlt-1, an endogenous inhibitor of vascular endothelial growth factor. J Cell Biochem 2004;93(1):120-32.

[36] Kabbinavar F, Hurwitz HI, Fehrenbacher L, et al. Phase II, randomized trial comparing bevacizumab plus fluorouracil (FU)/leucovorin (LV) with FU/LV alone in patients with metastatic colorectal cancer. J Clin Oncol 2003;21(1):60-5.

[37] Urbich C, Aicher A, Heeschen C, et al. Soluble factors released by endothelial progenitor cells promote migration of endothelial cells and cardiac resident progenitor cells. J Mol Cell Cardiol 2005;39(5):733-42.

[38] Gammill HS, Lin C, Hubel CA. Endothelial progenitor cells and preeclampsia. Front Biosci 2007;12:2383-94.

[39] Cao L, Jiao X, Zuzga DS, et al. VEGF links hippocampal activity with neurogenesis, learning and memory. Nat Genet 2004;36(8):827-35.

[40] Ferrara N, Houck K, Jakeman L, et al. Molecular and biological properties of the vascular endothelial growth factor family of proteins. Endocr Rev 1992;13(1):18-32.

[41] Miquerol L, Langille BL, Nagy A. Embryonic development is disrupted by modest increases in vascular endothelial 
growth factor gene expression. Development 2000;127(18):3941-6.

[42] Sela S, Itin A, Natanson-Yaron S, et al. A novel humanspecific soluble vascular endothelial growth factor receptor 1: cell-type-specific splicing and implications to vascular endothelial growth factor homeostasis and preeclampsia. Circ Res 2008;102(12):1566-74.
[43] Mazzone M, Dettori D, De Oliveira RL, et al. Heterozygous deficiency of PHD2 restores tumor oxygenation and inhibits metastasis via endothelial normalization. Cell 2009;136(5):839-51. 